\title{
Thermal degradation of polymer systems having liquid crystalline oligoester segment
}

\author{
Renato Matroniani* and Shu Hui Wang ${ }^{1}$ \\ ${ }^{1}$ Departament of Metallurgical and Materials Engineering, Polytechnic School, \\ Universidade de São Paulo - USP, São Paulo, SP, Brazil \\ *rmatroniani@usp.br
}

\begin{abstract}
Block copolymers and blends comprised by liquid crystalline oligoester and polystyrene were prepared and their thermal stability were characterized by thermogravimetric analysis (TGA). The samples have shown three main decomposition temperatures due to (1) lost of flexible chain and decomposition of mesogenic segment, (2) decomposition of polystyrene and (3) final decomposition of oligoester rigid segment. Both copolymers and polymer blends presented lower thermal stability compared to polystyrene and oligoester. The residual mass after heating at $600{ }^{\circ} \mathrm{C}$ in copolymers and polymer blends were lower than those found in the oligoesters. A degradative process of aromatic segments of oligoester induced by decomposition of polystyrene is suggested.
\end{abstract}

Keywords: blends, liquid crystalline oligoester, thermal degradation, thermal stability.

\section{Introduction}

The thermal behavior of liquid-crystalline polyesters (LCPs) has been subject of some papers due to their unique technological properties, such as low melting viscosity, self reinforcing mechanical properties, and high flame resistance ${ }^{[1-4]}$, which is verified by extensive char formation. The improvement of the mechanical properties of commodity and engineering thermoplastics upon addition of a small amount of liquid-crystalline polyester has been reported, even in the absence of miscibility in most of those systems ${ }^{[5,6]}$. Increased compatibility in polymer blends has been reported when a flexible liquid-crystalline polyester was employed and interfacial adhesion was observed ${ }^{[7,8]}$. In recent years, block copolymers containing liquid-crystalline segments and isotropic segments have been suggested to represent the frontier in this kind of polymer blends in terms of modulation of stiffness and size domains ${ }^{[9,10]}$.

Unlike LCPs, under thermal degradation conditions, most of thermoplastics and lightly crosslinked elastomers go through heat induced transformations that include hydrogen stripping, side group elimination, depolymerization to monomers and main chain rupture, followed by complete volatilization with no residue left. The influence of the presence of LCPs on the thermal degradative processes of thermoplastics is not well-known, especially in blends with isotropic-anisotropic segmented LCPs.

Thermogravimetric analysis (TGA) can supply information on the nature of the degradative reactions, if competitive or independent, and occasionally should be an useful tool to cast some light on the interactions present in a sample.

The thermal degradative process of aromatic polyesters containing a flexible segment has been already described. The degradation proceeds by free radical mechanism after the primary breakage of the ester linkage of the terephthalic acid (Figure 1). This mechanism involves a cyclic transition state with the hydrogen at the $\beta$ position, followed by a chain rupture process in which vinyl ester groups and carboxylic acids are formed ${ }^{[11-13]}$ (Figure 1). A second stage was reported to be the thermal scission of the mesogenic group with phenylenic residues formation. The final degradation stage corresponds to the decomposition and volatilization of the rigid segments.

In this paper, the thermal stability of a series of copolymers comprised by polystyrene and liquid-crystalline oligoester segments is studied. The copolymers present liquid crystalline properties and a nematic mesophase is observed by polarizing optical microscopy and thermal analysis and they are distinguished by the following general chemical structure (Figure 2).

The thermal degradative process of polystyrene is also previously described in many texbooks and a radical mechanism with random chain scission and chain terminal unzipping or depropagation is involved in the main process ${ }^{[14]}$. McNeill et al. ${ }^{[14]}$ demonstrated by a series of degradation studies of polystyrene, that between 200 and $300{ }^{\circ} \mathrm{C}$, the molecular weight of polystyrene is decreased without formation of volatile products, and above $300^{\circ} \mathrm{C}$, polystyrene degraded to products which can be separated into two main fractions: (1) volatile products comprising mainly monomer and small amounts of toluene and $\alpha$-methylstyrene, and (2) volatile products under vacuum and degradation temperature, the so-called cold ring fraction (CRF), comprising dimer, trimer and other short chain fragments. The secondary PS macroradical was confirmed to be the main source of volatile and CRF products. After $25 \%$ volatilization, intramolecular radical transfer becomes the main reaction and the proportion of CRF products is higher.

In our study, block copolymers and polymer blends comprised by the corresponding homopolymers, polystyrene and liquid-crystalline oligoester, were submitted to thermal analysis in order to understand the whole thermal degradative process. 


\section{Materials and Methods}

\subsection{Synthesis of block copolymers}

Thermotropic block copolymers, poly(methyl-1,4 dioxiphenylene-4,4'-dicarbonyl-1,10-dibenzoyl-decane)b-polystyrene, were prepared by a three step synthetic process $^{[15-17]}$. In a first step a dihydroxy-terminated oligoester (sample 1, Table 1) was prepared from a polycondensation reaction of 1,10-dibenzoyl-decane-4,4'-dicarboxylic acid in the presence of a molar excess of methyl-hydroquinone. In a second step, the dihydroxy-terminated oligoester formed was further esterified with azo-ciano-pentanoyl chloride in order to produce a free radical macroinitiator. The block copolymers (samples 2-5, Table 1) were obtained in a third step by radical polymerization of styrene carried out in the presence of the macroinitiator.

\subsection{Preparation of blends}

Polymer blends (samples 7-9, Table 1) were prepared by dissolution of oligoester (sample 1) and polystyrene Enichem PS1380 in chloroform (sample 6), followed by coprecipitation into methanol. Precipitated mixtures were vacuum dried at room temperature for 12 hours.
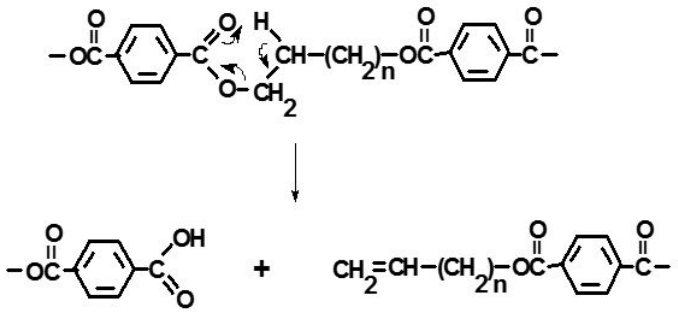

Figure 1. Initiation mechanism of terephthalic polyester decomposition containing a flexible segment ${ }^{[11-13]}$.

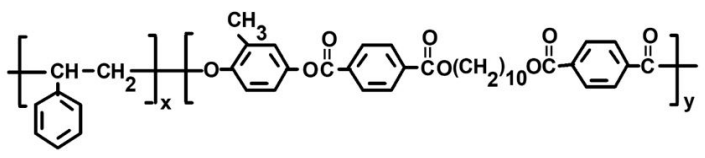

Figure 2. Block copolymer polystyrene-b-polyester.

Table 1. Homopolymers, copolymers and blends prepared in this work.

\begin{tabular}{cccc}
\hline Sample & Type & $\begin{array}{c}\text { Oligoester } \\
(\%)\end{array}$ & $\begin{array}{c}\text { Polystyrene } \\
(\%)\end{array}$ \\
\hline 1 & homopolymer & 100 & 0 \\
2 & copolymer & 63 & 37 \\
3 & copolymer & 39 & 61 \\
4 & copolymer & 29 & 71 \\
5 & copolymer & 16 & 84 \\
6 & homopolymer & 0 & $100^{\mathrm{a}}$ \\
7 & blend & 70 & $30^{\mathrm{a}}$ \\
8 & blend & 50 & $50^{\mathrm{a}}$ \\
9 & blend & 30 & $70^{\mathrm{a}}$ \\
\hline
\end{tabular}

${ }^{\mathrm{a} C}$ Comercial polystyrene PS1380 used in the blends.

\subsection{Characterization}

The chemical composition of the block copolymers (samples 2-5) was determined by ${ }^{1} \mathrm{H}-\mathrm{NMR}$ using a Varian Gemini 200 spectrometer.

The block copolymers (samples 2-5) were hydrolyzed to yield the correspondent polystyrene blocks (Table 2) by dispersing the copolymer $(0.5 \mathrm{~g})$ in methanol $(70 \mathrm{ml})$ together with sodium hydroxide $(7.0 \mathrm{~g})$. The complete hydrolysis $(3-4 \mathrm{~h})$ of the mixture was monitored by IR spectroscopy. The polystyrene residue was filtered, washed with methanol and dried.

The molar masses of oligoester, polystyrene and block copolymers were determined by gel permeation chromatography (GPC) in THF, using an LC10 Perkin-Elmer liquid chromatograph equipped with a Jasco 830-RI refractive index detector and $103 \AA$ and $104 \AA$ Waters ultrastyragel columns. Monodisperse polystyrene standards were used for calibration.

\subsection{Thermal analysis}

Thermogravimetry was carried out with a Mettler TG50 thermoanalyser, under dynamic nitrogen atmosphere of $50 \mathrm{ml} / \mathrm{min}$ flow and heating rate of $10^{\circ} \mathrm{C} / \mathrm{min}$. Sample size was 10 to $15 \mathrm{mg}$

DSC analysis were performed with a Mettler DSC-30 calorimeter under nitrogen atmosphere and heating and cooling cycles of $10^{\circ} \mathrm{C} / \mathrm{min}$. Sample size was 10 to $20 \mathrm{mg}$ and temperature range was $-20^{\circ} \mathrm{C}$ to $250^{\circ} \mathrm{C}$.

\section{Results and Discussions}

The relative composition of the two polymeric segments in the block copolymers was determined by ${ }^{1} \mathrm{H}-\mathrm{NMR}$ spectrometry (Table 2). The integration correspondent to the signal due to the benzene ortho-hydrogens, at $6.5 \mathrm{ppm}$, was used for polystyrene content determination, and the integration of the methylene oxide hydrogens signal, at $4.4 \mathrm{ppm}$, for the estimation of the oligoester.

Average molar masses of the polystyrene segments varied with the copolymer composition. Higher molar mass polystyrene observed in the block copolymers containing lower concentrations of oligoester, were due to the synthetical process adopted ${ }^{[16]}$.

DSC analysis of these materials confirmed the existence of a stronger intersegmental interaction in the copolymers than in the polymer blends (Figure 3). A decrease of the $T_{g}$ of the polystyrene phase in both polymeric systems, block copolymers and polymer blends, was observed and it is attributed to a partial miscibility of the oligoester in the polystyrene phase. In the block copolymers, the crystalline phase also changed. Broadening and shift of the melting $\left(\mathrm{T}_{\mathrm{m}}\right)$ and isotropization $\left(\mathrm{T}_{\mathrm{i}}\right)$ peaks were observed. The lowering of the isotropization temperature of oligoesters is atributted to the solvation of crystallites by polystyrene segments. The extension of the $\mathrm{T}_{\mathrm{i}}$ variation has been shown to be dependent on the size of both polymeric segments ${ }^{[16]}$. Blends of oligoester with the commercial polystyrene did not present any shift on the melting or isotropization temperature. 
Table 2. Average molar masses and compositions of block copolymers, homopolymers, and recovered polystyrene blocks.

\begin{tabular}{|c|c|c|c|c|c|}
\hline \multirow{2}{*}{ Sample } & \multirow{2}{*}{$\begin{array}{c}\text { Oligoester } \\
(\%)\end{array}$} & \multicolumn{2}{|c|}{ Block copolymer } & \multicolumn{2}{|c|}{ Polystyrene block } \\
\hline & & $\mathbf{M}_{w}$ & $M_{w} / M_{n}$ & $\mathbf{M}_{\mathbf{w}}$ & $M_{w} / M_{n}$ \\
\hline 1 & 100 & 4500 & 1.61 & - & - \\
\hline 2 & 63 & 10000 & 1.72 & 8000 & 1.39 \\
\hline 3 & 39 & 21000 & 2.22 & 17500 & 1.73 \\
\hline 4 & 29 & 54500 & 1.52 & 28500 & 1.71 \\
\hline 5 & 16 & 110500 & 1.48 & 69500 & 1.63 \\
\hline $6^{\mathrm{a}}$ & - & - & - & 228000 & 1.47 \\
\hline
\end{tabular}

${ }^{\mathrm{a} C}$ Comercial polystyrene PS1380 used in the blends.

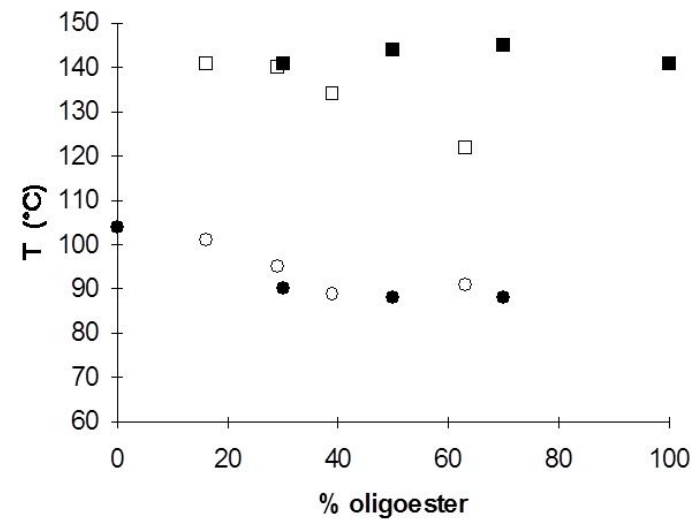

Figure 3. Transition temperature, $T_{g}$ and $T_{i}$, in block copolymers and polymer blends as a function of composition. $\mathrm{T}_{\mathrm{i}}$ in polymer blend ( $\bullet), T_{i}$ in block copolymer $(\square), T_{g}$ in polymer blend $(\bullet)$ e $\mathrm{T}_{\mathrm{g}}$ in block copolymer $(\mathrm{O})$.

These results clearly indicate an extensive miscibility in the polystyrene amorphous phase, in the block copolymer or polymer blend. However, a separated oligoester phase was still present as isotropization temperature was observed. Although constant in the polymer blends, and indicating essentially no significant intermolecular interactions, $T_{i}$ in copolymers steadily decreased as the polystyrene segment length decreased from $\mathrm{M}_{\mathrm{w}}=28500 \mathrm{~g} / \mathrm{mol}$ to $\mathrm{M}_{\mathrm{w}}=8000 \mathrm{~g} / \mathrm{mol}$, suggesting again segmental interaction within this oligoester phase.

The oligoester, the block copolymers and the polymer blends under the conditions of the thermogravimetric analysis presented two main weight losses (Figure 4). The polystyrene presented only one sharp weight loss, primarily owing to the depropagation mechanism, as described in literature (Figure 4). The thermal decomposition of flexible thermotropic polyester based on a mesogenic triad unit with three aromatic rings has been described to occur in two fundamental steps in the path to a carbonaceous residue ${ }^{[17]}$. According to the authors ${ }^{[17]}$, the first step is initiated by fragmentation of the flexible segment and vaporization of dienes, however immediately before the second step these fragments are no longer detected by mass spectroscopy and elimination of $\mathrm{CO}_{2}$ is observed after reaching $400{ }^{\circ} \mathrm{C}$, with a second maximum rate around $460{ }^{\circ} \mathrm{C}$, as observed for sample 1 , oligoester (Figure 4).

Table 3 presents the results of TGA as a function of copolymer composition.

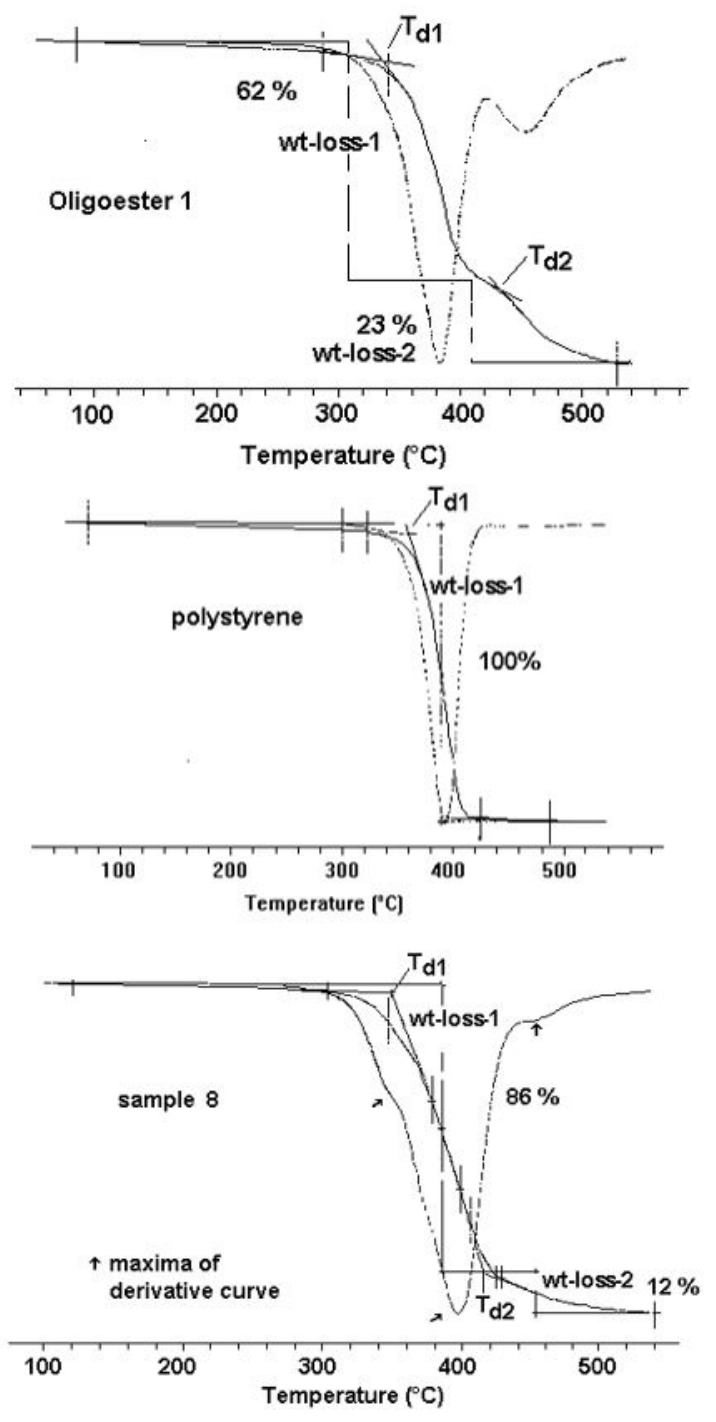

Figure 4. TGA of the homopolymers, sample 1 (oligoester 1) and polystyrene Enichem PS1380, and blend of oligoester 1 and polystyrene.

At the onset of the degradation, $\mathrm{T}_{\mathrm{d} 1}$, at very low weight loss, the degradation mechanism is still governed by intermolecular radical transfer. This temperature reflects the intermolecular interactions and is dependent on the molar mass of the sample. 
Table 3. TGA of block copolymers prepared from oligoester 1 .

\begin{tabular}{|c|c|c|c|c|c|c|}
\hline Sample & $\begin{array}{c}\% \\
\text { oligoester }\end{array}$ & $\begin{array}{l}\mathbf{T}_{\mathrm{d} 1} \\
{ }^{\circ} \mathbf{C}\end{array}$ & $\begin{array}{c}\text { wt-loss-1 } \\
\%\end{array}$ & $\begin{array}{l}\mathbf{T}_{\mathrm{d} 2} \\
{ }^{\circ} \mathbf{C}\end{array}$ & $\begin{array}{c}\text { wt-loss-2 } \\
\%\end{array}$ & $\begin{array}{c}\text { residue } \\
\%\end{array}$ \\
\hline 1 & 100 & 353 & 62 & 426 & 23 & 15 \\
\hline 2 & 63 & 352 & 81 & 402 & 23 & 0 \\
\hline 3 & 39 & 336 & 68 & 412 & 32 & 0 \\
\hline 4 & 29 & 338 & 77 & 419 & 23 & 0 \\
\hline 5 & 16 & 361 & 100 & - & 0 & 0 \\
\hline
\end{tabular}

$\mathrm{T}_{\mathrm{d} 1}$ temperature at the first onset; $\mathrm{T}_{\mathrm{d} 2}$ temperature at the second onset; wt-loss-1 weight loss in the first stage; and wt-loss-2 weight loss in the second stage.

Table 4. TGA of blends of polystyrene 6 and oligoester 1.

\begin{tabular}{|c|c|c|c|c|c|c|}
\hline Sample & $\begin{array}{c}\% \\
\text { oligoester }\end{array}$ & $\begin{array}{l}\mathbf{T}_{\mathrm{d} 1} \\
{ }^{\circ} \mathbf{C}\end{array}$ & $\begin{array}{c}\text { wt-loss-1 } \\
\%\end{array}$ & $\begin{array}{l}\mathbf{T}_{\mathrm{d} 2} \\
{ }^{\circ} \mathbf{C}\end{array}$ & $\begin{array}{c}\text { wt-loss-2 } \\
\%\end{array}$ & $\begin{array}{c}\text { residue } \\
\%\end{array}$ \\
\hline 6 & 0 & 372 & 100 & - & 0 & 0 \\
\hline 7 & 70 & 335 & 71 & 417 & 16 & 13 \\
\hline 8 & 50 & 349 & 86 & 415 & 12 & 2 \\
\hline 9 & 30 & 361 & 84 & 413 & 13 & 3 \\
\hline
\end{tabular}

$\mathrm{T}_{\mathrm{d} 1}$ temperature of first curve inflection; $\mathrm{T}_{\mathrm{d} 2}$ temperature of the second deflection; wt-loss-1 weight loss in the first stage; and wt-loss-2 weight loss in the second stage.

A lowering in the thermal stability in both copolymers and polymer blends was observed, as the first weight loss derivative curve exposed a shoulder around $360^{\circ} \mathrm{C}$ (exemplified by sample 8 , indicated in Figure 4 ) and a total weight loss in the first stage over $70 \%$. The residue after heating to $600^{\circ} \mathrm{C}$ in copolymers and blends were also lower than that observed for the oligoester.

Such behavior suggests that a degradative process of the aromatic segments of the oligoester was induced by the radicals formed during the fast polystyrene decomposition.

The relative higher $\mathrm{T}_{\mathrm{d} 1}$ observed for sample $\mathbf{2}$ compared to other samples, copolymers and blends, is unexpected because of the higher miscibility observed in both crystalline and amorphous phases (Figure 3 ). For this sample, a thermal degradation due to intermolecular radical transfer seems to be limited, maybe because of its comparatively lower molar mass (Table 2).

Samples $\mathbf{3}$ and $\mathbf{4}$ with comparable polystyrene segment lengths and miscibility behaviors (Table 2 and Figure 3), were also similar in thermal induced decomposition and both degradation steps presented comparable onset temperatures. Accordingly to its low oligoester content, sample $\mathbf{5}$ showed the expected higher thermal stability compared to $\mathbf{3}$ and $\mathbf{4}$.

The dependence of the degradation temperature of polystyrene on its molar mass is well known, higher stability is expected for the higher molar mass samples. However, in the polymer blends, the molar masses of the components were kept constant and the decomposition behavior should be only ascribed to the composition of each blend.

Table 4 shows that the onset of degradation was dependent on the oligoester concentration when molar masses were kept constant. The increase in oligoester concentration decreased the thermal stability of those blends.

A comparison between copolymer $\mathbf{4}$ and blend $\mathbf{9}$ shows that the same concentration of oligoester is present, however, the thermal stability of copolymer 4 was much lower. The lower thermal stability observed for copolymer should be attributed to the existence of stronger segmental interaction and lower molar mass, reinforcing a mutual degradative process.

\section{Conclusions}

Compared to the homopolymers, LC-oligoester and polystyrene, the block copolymers and the polymer blends having liquid crystalline segments presented a lower thermal stability. The lower thermal stability observed is attributed to the existence of an interaction between the two types of polymer chain, polystyrene and oligoester. It is suggested that in these polymer systems, under thermal induced degradative conditions, transport of radical species between phases favored the degradation propagation. The even higher instability of the copolymers compared to blends is believed to be a result of lower molar mass and stronger segmental interaction, as it was observed by DSC analysis, causing an intensified mutual polymer degradation process. However, the judicious incorporation of LCP to commodity polymers may be a potential procedure to achieve standard thermoplastics with incremented thermal resistance, as char formation is common in those systems.

\section{Acknowledgements}

The authors thank Brazilian CAPES and CNPq for financial support.

\section{References}

1. Jin, X., \& Chung, T. S. (1999). Thermal decomposition behavior of main-chain thermotropic liquid crystalline polymers, vectra A-950, B-950, and Xydar SRT-900. Journal of Applied Polymer Science, 73(11), 2195-2207. http://dx.doi. org/10.1002/(SICI)1097-4628(19990912)73:11<2195::AIDAPP17>3.0.CO;2-3.

2. Mandal, P. K., Siddhanta, S. K., \& Chakraborty, D. (2011). Engineering properties of compatibilized polypropylene/ 
liquid crystalline polymer blends. Journal of Applied Polymer Science, 124(6), 5279-5285.

3. Wei, P., Wang, L., Wang, X. H., Chen, Y. W., Wang, Y. P., \& Wang, Y. M. (2014). Nonisothermal and isothermal oxidative degradation behavior of thermotropic liquid crystal polyesters containing kinked bisphenol $\mathrm{AF}$ and bisphenol A units. High Performance Polymers, 26(8), 935-945. http://dx.doi. org/10.1177/0954008314535645.

4. Chi, Z. G., Yao, X. D., Zhang, Y., \& Xu, J. R. (2005). Thermal decomposition kinetics of thermotropic liquid crystalline polyesterimides. Journal of Applied Polymer Science, 98(6), 2467-2472. http://dx.doi.org/10.1002/app.22447.

5. Mithal, A. K., Tayebi, A., \& Lin, C. H. (1991). In situ composite fibers: Blends of liquid crystalline polymer and poly (ethylene terephthalate). Polymer Engineering and Science, 31(21), 1533-1538. http://dx.doi.org/10.1002/pen.760312105.

6. Mehta, S., \& Deopura, D. L. (1993). Fibers from blends of PET and thermotropic liquid-crystalline polymer. Polymer Engineering and Science, 33(14), 931-936. http://dx.doi. org/10.1002/pen.760331410.

7. Shin, B. Y., \& Chung, I. J. (1990). Polymer blend containing a thermotropic polyester with long flexible spacer in the main chain. Polymer Engineering and Science, 30(1), 22-29. http:// dx.doi.org/10.1002/pen.760300105.

8. Shin, B. Y., Jang, S. H., Chung, I. J., \& Kim, B. S. (1992). Mechanical-properties and morphology of polymer blends of poly(ethylene-terephthalate) and semiflexible thermotropic liquid-crystalline polyesters. Polymer Engineering and Science, 32(1), 73-79. http://dx.doi.org/10.1002/pen.760320112.

9. Heitz, T., Rohrbach, P., \& Höcker, H. (1989). Rigid rods with flexible side-chains - a route to molecular reinforcement. Macromolecular Chemistry and Physics, 190(12), 3295-3316. http://dx.doi.org/10.1002/macp.1989.021901226.

10. Kobayashi, T., Sato, M., Takeno, N., \& Mukaida, K. (1992). Synthesis and liquid crystallinity of thermotropic polycarbonatepolystyrene graft-copolymers. European Polymer Journal, 28(9), 1105-1110. http://dx.doi.org/10.1016/0014-3057(92)90062-7.
11. Lum, R. M. (1979). Thermal-decomposition of poly(butylene terephthalate). Journal of Polymer Science. Part A, Polymer Chemistry, 17(1), 203-213. http://dx.doi.org/10.1002/ pol.1979.170170120.

12. Foti, S., Giuffrida, M., Maravigna, P., \& Montaudo, G. (1984). Direct mass-spectrometry of polymers. 11. Primary thermal fragmentation processes in aromatic aliphatic polyesters. Journal of Polymer Science. Part A, Polymer Chemistry, 22(6), 1217-1229. http://dx.doi.org/10.1002/pol.1984.170220602.

13. Montaudo, G., Puglisi, C., Scamporrino, E., \& Vitalini, D. (1986). Thermal degradation of aromatic-aliphatic polyethers. 1. Direct pyrolysis-mass spectrometry. Macromolecules, 19(3), 870-882. http://dx.doi.org/10.1021/ma00157a067.

14. McNeill, I. C., Zulfiqar, M., \& Kousar, T. (1990). A detailed investigation of the products of the thermal-degradation of polystyrene. Polymer Degradation \& Stability, 28(2), 131-151. http://dx.doi.org/10.1016/0141-3910(90)90002-O.

15. Wang, S. H., Coutinho, F. M. B., Galli, G., \& Chielllini, E. (1996). Copolímeros em bloco termotrópicos poliestireno Poli(Metil-1,4-Dioxifenileno-4,4-Dicarbonil-1,10-DibenzoilOxi-Decano): 1. Síntese e caracterização. Polímeros: Ciência e Tecnologia, 6(4), 38-44.

16. Wang, S. H., Coutinho, F. M. B., Galli, G., \& Chiellini, E. (1995). Synthesis and characterization of polystyrene-polyester liquid-crystalline block-copolymers. Polymer Bulletin, 34(5-6), 531-537. http://dx.doi.org/10.1007/BF00423348.

17. Ellis, G., Marco, C., del Pino, J., \& Goméz, M. A. J. (1998). Thermal stability and degradation mechanism for two mainchain liquid crystal polyesters - A TG-MS study. Journal of Thermal Analysis and Calorimetry, 52(3), 683-695. http:// dx.doi.org/10.1023/A:1010185817984.

Received: Dec. 23, 2015

Revised: Apr. 18, 2016 Accepted: June 29, 2016 